A N N A L E S Annales de Bretagne et des Pays de l'Ouest

\title{
Les Justices seigneuriales en Anjou et dans le Maine à la fin $\mathrm{du}$ Moyen Âge
}

\section{Martine Charageat}

\section{(2) OpenEdition}

1 Journals

Édition électronique

URL : http://journals.openedition.org/abpo/2342

DOI : $10.4000 /$ abpo.2342

ISBN : 978-2-7535-1852-0

ISSN : 2108-6443

Éditeur

Presses universitaires de Rennes

Édition imprimée

Date de publication : 30 mars 2012

Pagination : 199-201

ISBN : 978-2-7535-1850-6

ISSN : 0399-0826

\section{Référence électronique}

Martine Charageat, "Les Justices seigneuriales en Anjou et dans le Maine à la fin du Moyen Âge », Annales de Bretagne et des Pays de l'Ouest [En ligne], 119-1 | 2012, mis en ligne le, consulté le 21 décembre 2020. URL : http://journals.openedition.org/abpo/2342 ; DOI : https://doi.org/10.4000/abpo.2342

Ce document a été généré automatiquement le 21 décembre 2020.

(c) Presses universitaires de Rennes 


\title{
Les Justices seigneuriales en Anjou et dans le Maine à la fin du Moyen Âge
}

\author{
Martine Charageat
}

\section{RÉFÉRENCE}

Isabelle Mathieu, Les Justices seigneuriales en Anjou et dans le Maine à la fin du Moyen Âge, Rennes, PUR, 2011, 393 p. (ISBN 978-27535-1282-5).

1 Unis par une parenté de droit coutumier, le Maine et l'Anjou sont étudiés conjointement par Isabelle Mathieu dans cette enquête sur les justices seigneuriales à la fin du Moyen Âge. Les bornes chronologiques de celle-ci sont clairement explicitées dès l'introduction : le début du XIV e siècle, date de la conservation la plus ancienne des actes de la pratique, et l'année 1539 qui renvoie à l'ordonnance de Villers-Cotterêts, laquelle a eu pour effet de "bousculer» (p. 21) les juridictions seigneuriales au profit de la souveraineté du roi qui prétend par exemple en contrôler l'attribution. Relevant des justices concédées, agissant avec, contre ou en résistance à la justice royale, sinon à la souveraineté judiciaire du roi, les tribunaux seigneuriaux fonctionnent malgré la genèse de l'État moderne. En effet, L'auteur met en évidence le bon fonctionnement de ces juridictions inférieures longtemps délaissées par les médiévistes, et plus encore par les «bas médiévistes" (encore que ce constat, vrai pour la France, ne vaille pas pour l'Angleterre ou l'Espagne). Ainsi le recours aux travaux des modernistes, plus nombreux (justices de villages, de proximité etc.) s'imposait-il. L'étude des justices seigneuriales en Anjou et dans le Maine doit prendre en compte un double pluralisme : institutionnel (imbrication des structures judiciaires et des juridictions) et juridique (empilement des droits, coutumes, usages locaux). Les échelles de travail se superposent elles aussi au sein de chaque axe d'étude. L'ouvrage se compose de trois parties déterminées par la volonté de l'auteure de comprendre le fonctionnement des tribunaux seigneuriaux, leur composition, l'usage qui en est fait par les justiciables et la justice effectivement rendue en leur sein. Pour ce faire, elle emploie des méthodes déjà éprouvées, combinant analyse quantitative et qualitative des données extraites des 
registres dépouillés et méthode prosoprographique appliquée à l'étude des hommes, sans oublier les apports de la micro-histoire.

Liées à la seigneurie, ces justices proches des habitants se distinguent par leurs droits et leurs institutions qu'I. Mathieu aborde en première partie, commençant par les sources qui en permettent l'étude, avant d'en décortiquer les limites, les prérogatives et les compétences. Contre la position de Bernard Guenée, I. Mathieu a pris le parti de dépouiller de façon systématique les sources normatives et les actes de la pratique judiciaire rassemblés pour son enquête. Les registres d'audience, aux causes et d'amendes, ont été soigneusement lus et "passés à la moulinette " des statistiques. Entre description des sources, rouleaux de parchemins cousus et registres de papiers, et description de la manière de noter le déroulement des affaires (style, datation, éléments consignés), l'auteure note le soin grandissant apporté entre le XIV ${ }^{\mathrm{e}}$ siècle et le $\mathrm{XV}^{\mathrm{e}}$ siècle à la mise par écrit des actes rédigés par les justices seigneuriales, servant en cela le but des contemporains d'en faire des actes de la pratique, au service de la mémoire des communautés de justiciables et des praticiens du droit. En définissant les contours des juridictions seigneuriales, l'enchevêtrement hiérarchisé des cours et de leurs compétences respectives - variables et réparties entre justice foncière, féodale et seigneuriale ou justicière (encore que ce point reste un peu flou pour le néophyte) - et en marquant la part du droit coutumier, I. Mathieu met son objet d'étude en corrélation avec les autres juridictions supérieures, en particulier celle du roi. Rapport de force et respect alternent selon les angles d'approche. Si l'appel devant les officiers du roi n'est permis qu'à condition que la procédure ait préalablement épuisé tous les recours locaux, le roi n'hésite pas à imposer la souveraineté de sa loi à l'occasion, sinon contre les coutumes d'Anjou et du Maine qui prévalent longtemps, du moins contre l'acte juridique contredisant ou enfreignant une ordonnance royale (ordonnance de Blois de 1499).

3 Dans une seconde partie, I. Mathieu s'attache à éclairer l'organisation des audiences seigneuriales et la composition du personnel judiciaire. Les différences ne sont pas flagrantes entre le Maine et l'Anjou. Entre recommandations royales et efforts réellement consentis par les seigneurs, entre prescriptions émanant des coutumiers et renseignements fournis par les registres, l'auteure met en lumière le rythme des audiences. Elles se partagent entre assises et plaids sans qu'il soit possible de distinguer des différences nettes dans l'emploi des deux termes. Le rythme des sessions semble inspiré davantage par le calendrier liturgique qu'agricole. La localisation des audiences montre une justice encore itinérante et capable de se porter, si besoin, aux marges des frontières territoriales dans le souci d'être accessible à tous ceux qui ont besoin d'elle. Les lieux choisis le sont autant en raison de leur caractère pratique (espaces abrités), que symbolique (espaces sacrés) et, parfois, en relation avec des enjeux de politique vassalique. L'inscription dans le paysage d'une justice parfois sédentarisée se fait pas le biais de la prison, des gibets et autres fourches patibulaires dont la taille et le nombre de piliers servent à manifester la puissance de leur détenteur; mais sans qu'on sache pourquoi, certains seigneurs justiciers n'en font pas construire, alors même qu'ils le pourraient. Quant au personnel judiciaire, il ressort du tableau élaboré à l'issue de l'application soigneuse des méthodes de la prosoprographie, qu'il se partage entre offices inféodés, affermés ou gagés. Dans un deuxième temps, on comprend bien que se distinguent les présidents d'audience, plus ou moins gradués en droit (certains étant très au fait du droit coutumier), d'un personnel subalterne (sergents et recors), 
auxquels s'ajoutent des greffiers et des procureurs. L'auteure indique en conclusion de cette deuxième partie l'intérêt de ce tableau : montrer que la justice seigneuriale est active et son exercice hautement public; qu'elle se soucie de régler des questions extrêmement variées et pas seulement de préserver les droits des seigneurs.

Cette dimension est développée dans la troisième partie où l'on découvre le droit procédural appliqué et le déroulement concret des procès, l'action des parties litigantes, l'issue des litiges et des crimes portés à la connaissance de ces tribunaux, ainsi que les "visages de la délinquance et de la criminalité » (p. 23). Les cours seigneuriales sont amenées à connaître des questions relatives à l'administration des seigneuries, ou relevant de la juridiction civile gracieuse, de la justice contentieuse civile et de la justice criminelle. Beaucoup de procès sont menés au nom du seigneur, ce qui indique que les justiciables n'arrivent au tribunal qu'en dernier ressort, pour débloquer des situations litigieuses tendues que des solutions extra-judiciaires ont échoué à régler. Enfin, l'issue des affaires se solde plus souvent par des amendes pécuniaires que par des peines lourdes. Le constat de la rareté des exécutions capitales rejoint celui établi par d'autres chercheurs dans d'autres juridictions, à commencer par Claude Gauvard dans celle du Parlement de Paris. I. Mathieu déplore de ne pouvoir évaluer avec précision le poids et l'influence de l'activité judiciaire de ces seigneuries en tant que « justice service ", « justice pouvoir » et « justice argent» (p. 352), les deux premières notions étant empruntées à Xavier Rousseaux. Cela n'enlève rien à l'intérêt que revêt son travail de nous amener au plus près d'une justice « de base » et au plus près de l'expérience judiciaire de la population ordinaire du Maine et de l'Anjou à la fin du Moyen Âge.

Partagé entre l'étude classique de l'histoire des institutions, du droit et de la procédure, et l'analyse renouvelée de l'histoire du crime et de la violence, voire de la résolution des conflits et des justices de proximité, le plan ne fait pas ressortir immédiatement l'ambition de ce travail telle qu'elle est énoncée en préface et en introduction : mettre fin au préjugé historiographique ancien selon lequel les justices seigneuriales seraient « inefficaces, au personnel incompétent et vénal et aux décisions arbitraires » (JeanMichel Matz). Discours historiographique qui aurait sans doute mérité un rappel plus détaillé et une mise en abîme plus systématique des résultats obtenus par l'auteure. Le but de cet énorme travail de recherche, dont l'ampleur réside dans la quantité de données fournies par les registres étudiés, est de montrer que les tribunaux seigneuriaux dans le Maine et en Anjou à la fin du Moyen Âge étaient bien organisés, fonctionnaient pleinement et avec efficacité grâce à leurs propres personnels et à la confiance que leur faisaient les justiciables. Sans être les ennemis de la construction étatique en cours, ils n'ont pas été facilement mis sous tutelle par la monarchie, sans doute parce qu'ils n'étaient ni faibles, ni désorganisés et qu'ils ne manquaient pas de personnel compétent. Au terme de cette enquête minutieuse, c'est probablement cette dernière question, qu'on pouvait poser en termes de résistance ou d'opposition, qui apparaît la moins approfondie. On aurait aimé en savoir davantage sur les relations entre justice seigneuriale et cours supérieures, mais la nature et l'état de conservation des sources d'une part, le temps dévolu aujourd'hui à la réalisation des thèses de doctorat d'autre part, ne le permettaient sans doute pas. 